DOI: http://10.18315/argumentum.v12i1.21407

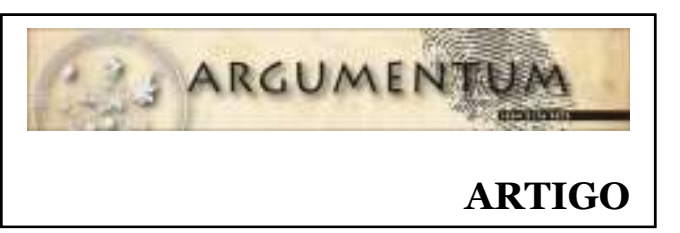

\title{
Direito Penal do Inimigo e política brasileira de encarceramento em massa
}

\author{
The Criminal Law of the Enemy and the Brazilian policy of mass incarceration \\ Ley Penal del Enemigo y política brasileña de encarcelamiento masivo
}

Lucas Andres Arbage*

https://orcid.org/oooo-0oo1-6544-1139

\begin{abstract}
Resumo: Este artigo tem como objetivo discorrer acerca do direito penal e a teoria do direito penal do inimigo, proposta por Günther Jakobs, à luz do contemporâneo direito penal crítico. Analisa-se a atual conjuntura da política criminal brasileira, bem como da teoria do direito penal do inimigo. Expõe-se os malefícios de uma política criminal de caráter exclusivamente repressiva, sua relação com a mídia e os riscos decorrentes das leis que são criadas em caráter emergencial, ferindo direitos fundamentais. Debatem-se os principais aspectos e críticas da teoria do direito penal do inimigo. Conclui-se que a justiça penal deve-se basear num posicionamento político-criminal minimalista e garantista, condizente com o Estado democrático de direito. A metodologia empregada foi a pesquisa bibliográfica e documental, composta pela análise de documentos oficiais, ordenamento jurídico e doutrina.

Palavras-chave: Direito Penal do Inimigo. Direito Penal. Criminologia. Segurança Pública. Direito Processual Penal.
\end{abstract}

Abstract: This article discusses criminal law and the theory of the Criminal Law of the Enemy, proposed by Günther Jakobs, in the light of contemporary critical criminal law. The current Brazilian criminal policy is analyzed, as well as the theory of the Criminal Law of the Enemy. The harm caused by an exclusively repressive criminal policy, its relationship with the media and the risks arising from the laws that are being created on an emergency basis and which undermine fundamental rights, are exposed. The main aspects and critiques of the theory underlying the Criminal Law of the Enemy theory are debated. It concludes that criminal justice must be based on a minimalist and guaranteed criminal-political position, consistent with the democratic rule of law. The methodology used was bibliographic and documentary research, composed of the analysis of official documents, legal orders and doctrine.

Keywords: Criminal Law of the Enemy. Criminal Law. Criminology. Public security. Criminal Procedural Law.

Submetido em: 04/12/2018. Revisado em: 20/05/2019. Aceito em: 27/12/2019.

\footnotetext{
* Advogado. Mestre em Educação, pela Universidade Federal da Fronteira Sul (UFFS, Chapecó, Brasil ). SC484 - km 2, Chapecó (SC), CEP: 89815-899. E-mail: lucasaarbage@hotmail.com.

(cc) EY (C) A(s) Autora(s)/O(s) Autor(es). 2019 Acesso Aberto Esta obra está licenciada sob os termos da Licença Creative Commons Atribuição 4.0 Internacional (https://creativecommons.org/licenses/by/4.o/deed.pt_BR), que permite copiar e redistribuir o material em qualquer suporte ou formato, bem como adaptar, transformar e criar a partir deste material para qualquer fim, mesmo que comercial. O licenciante não pode revogar estes direitos desde que você respeite os termos da licença.
} 


\section{Introdução}

Tste artigo objetiva refletir acerca da teoria do direito penal do inimigo, criada por Günther Jakobs, contextualizando-se a temática com o discurso penal maximalista e seus desdobramentos.

Abordam-se, inicialmente, aspectos contemporâneos da política criminal brasileira, como, por exemplo, os obstáculos para que a mesma se consubstancie e respeite os direitos básicos previstos aos cidadãos que vivem num país que se intitula como sendo um Estado democrático de direitos.

Nesse contexto, constata-se a formação de um direito penal simbólico, diante de um cenário legitimador de reformas legislativas e administrativas, no sentido de esvaziar as garantias processuais do acusado, e ao reforço dos poderes investigatórios e punitivos estatais. A criminalização de algumas condutas e/ou o aumento das penas, algumas em função da pressão exercida pela mídia e/ou pela visibilidade política da medida, são algumas das causas da crescente expansão do direito penal e do encarceramento em massa ocorrido nos últimos anos no Brasil.

Encontra-se respaldo e um lócus fértil para o preconizado pela teoria do direito penal do inimigo, já que, através da mesma, revogam-se as garantias materiais e processuais, até então asseguradas pelo ordenamento jurídico vigente, em razão da periculosidade e nocividade que o inimigo apresentaria para a sociedade. Jakobs e Cancio Meliá (2009) asseveraram que existem dois tipos distintos de delinquentes, quais sejam, as pessoas e os inimigos. Todo o processo envolvendo investigações, julgamentos e cumprimento de pena, é extremamente distinto e de acordo com a classificação da pessoa que estará sendo julgada. Caso seja uma pessoa, entende-se que a mesma realizou apenas um erro, fazendo jus às garantias constitucionais e aos seus direitos básicos. Todavia, se o cidadão em questão for enquadrado como um inimigo sofrerá penas cruéis e não terá seus direitos básicos respeitados, sendo declarada guerra contra si e, se possível, sendo eliminado.

A metodologia empregada foi a pesquisa bibliográfica e documental, composta pela análise de documentos oficiais, como, por exemplo, pelo Infopen do ano de 2017, documento emitido pelo Ministério da Justiça brasileiro, do ordenamento jurídico (código penal brasileiro de 1940, lei oㅜ 11.343 de 2006) e doutrina, através de diversos autores elencados ao longo do presente trabalho, que são referência na temática (INFOPEN, 2017).

Abordam-se, a seguir, mais detalhadamente, aspectos contemporâneos acerca da política criminal brasileira.

\section{Aspectos contemporâneos da política criminal brasileira}

Atualmente a sociedade tem se democratizado, apresentando crescente interesse por temáticas como crime e segurança pública. De acordo com Hungria (1978) o conceito 
jurídico de crime é importante, mas, controverso na moderna doutrina penal, sendo que por Durkheim (1999), entendia-se que, no final do século XIX, configurava-se o crime no momento que uma atitude atentasse contra a esfera da consciência coletiva. Por conseguinte, estabeleceu-se, de acordo com Hobbes (1993), que a gerência do poder punitivo ficaria a cargo do Estado, superando-se a época da vingança divina e/ou privada.

Portanto, as atitudes criminosas apresentariam uma característica idêntica: a ofensa à coletividade. Dado a ocorrência da referida ofensa, como forma de reafirmar os valores presentes na sociedade, de acordo com Durkheim (1999), utilizava-se a pena, sem qualquer intuito de ressocialização ou voltada para o criminoso. Realizando uma retomada histórica dos sistemas repressivos, conclui-se que somente na modernidade houve limites formalmente constituídos para a ação punitiva pelo sistema sancionatório vigente.

Chegando-se num momento contemporâneo, ainda que possam existir dispositivos legais nos ordenamentos jurídicos que, em tese, consubstanciem um viés ressocializador da pena e das instituições prisionais, na prática a vivência é diferente. Prova disso é que se constata um crescente número de pessoas que estão privadas de liberdade, já contando, em nível mundial, com mais de 11 milhões de pessoas nessa condição, com crescimento de $20 \%$ durante os anos 2000 e 2016 (WALMSLEY, 2016).

A política criminal apresenta significativa tendência à expansão do poder punitivo, gerando um encarceramento em massa, em grande parte influenciada pelo padrão norte-americano representado pela política da lei e ordem, posto que este país é o maior encarcerador do mundo e influencia muitas nações dado seu poder e representação no atual cenário. Com a referida expansão do poder punitivo, as retóricas de guerra (às drogas e ao terrorismo, por exemplo) foram expandidas e os inimigos da sociedade tomaram nova forma.

No cenário nacional, existem exemplos claros de que a partir da década de oitenta, do século $\mathrm{XX}$, esse fenômeno se intensificou sobremaneira e de forma crescente, como, por exemplo, através: do código penal, decreto-lei no: 2.848 , de 7 de dezembro de 1940; pela lei de crimes ambientais, no: 9.605, de 12 de fevereiro de 1998; pela lei no 11.343, de 23 de agosto de 2006 (lei de drogas), na qual se inserem dispositivos atinentes ao tráfico de entorpecentes e sua repressão (destaca-se que se considera essa lei como principal responsável pela explosão do número de presidiários no Brasil), dentre diversos outros dispositivos que serão abordados com mais detalhes no decorrer deste artigo (BRASIL, 1940; 2006).

Comprova-se que a lei de drogas foi um dos principais fatores que aumentaram o número de presos no Brasil, na medida em que, por exemplo, observa-se que o número de presos por tráfico de drogas aumentou 508\% em 12 anos no estado de São Paulo, segundo o Ministério da Justiça e Secretaria da Administração Penitenciária, por meio da Lei de Acesso à Informação. No mesmo período, entre 2005 e 2017, a população prisional do estado aumentou 64\% (INFOPEN, 2017). Isto ocorre, principalmente, pelo subjetivismo que a presente lei confere, por exemplo, ao não delimitar, ao certo, como se configura traficante ou simplesmente usuário de drogas. 
Configura-se no cenário atual um direito penal simbólico, a partir de um contexto legitimador de reformas legislativas e administrativas direcionadas ao esvaziamento das garantias processuais do suspeito e/ou acusado e ao reforço dos poderes investigatórios e punitivos estatais. Isso vai ao encontro ao defendido pela teoria do direito penal do inimigo. Assim, a criminalização de algumas condutas é uma das causas da crescente expansão do direito penal (BOLDT; KROHLING, 2008).

De acordo com Zaffaroni ${ }^{1}$, infelizmente se tem presenciado a edição de leis a partir da ocorrência de crimes de repercussão na mídia, sem o cuidado e/ou o debate necessário, pois são editadas às pressas e somente com intuito de satisfazer a sede de vingança da sociedade, aniquilando-se os códigos penais. Na política de espetáculo, o político precisa e quer se projetar na televisão, sendo que o importante para ele é o impacto que a lei vai causar, pois a isso será, proporcionalmente, o seu tempo de exposição. Assim, estigmatiza-se um grupo de pessoas e o torna o bode expiatório momentâneo, sendo os denominados delinquentes comuns. Através de uma paranoia social, incentiva-se a vingança desenfreada, gerando um encarceramento em massa dessa parcela populacional.

Exemplifica-se a referenciada distorção, por parte da mídia, da realidade fática envolvendo o sistema prisional através da comprovação quanto à origem do número total de mortes violentas e intencionais (correspondente à soma das vítimas de homicídio doloso, latrocínio, lesão corporal seguida de morte e mortes decorrentes de intervenções policiais em serviço e fora) no Brasil. No ano de 2018 , houve 48.951 mortes desta natureza, maior número já registrado na história nacional. Ocorre que, diferentemente do vinculado na mídia, o percentual de mortes provocadas em assaltos é extremamente inferior ao comparado com o de acidentes de trânsito. Em 2018, foram 1.929 casos de roubos seguidos de morte (latrocínios). Já as mortes por acidentes de trânsito somaram 34.236, no ano de 2017 (FBPS, 2019). Todavia, na exposição midiática o destaque e o tempo destinado para as mortes destas naturezas não é proporcional às referidas proporções.

Portanto, o que se constata é uma atual sociedade do espetáculo, na qual a mídia emprega uma linguagem para influenciar a opinião pública (BARATTA, 2002). Para tanto, utiliza-se da comoção e do sensacionalismo para apreciar a violência e exacerbar a importância do crime e da justiça penal. Carvalho (2015) também analisou e criticou o modelo punitivista e populista presente em na sociedade brasileira:

Os modelos populistas normalmente estão vinculados a um líder carismático. Os sistemas penais populistas, porém, são edificados a partir da confluência de inúmeras 'lideranças carismáticas' no melhor estilo 'empresários morais': âncoras autoritários de programas de grande audiência (agência de comunicação social); parlamentares 'law and order' e gestores caudilhescos (agência legislativa e executiva); policiais inquisidores, promotores 'tolerância zero' e juízes decisionistas (agências policial e judicial). O populismo punitivo é baseado no marketing da pena, produto cultural de alto consumo nas sociedades contemporâneas

${ }^{1}$ Disponível em entrevista realizada pelo Consultor Jurídico - Conjur (ZAFFARONI, 2017). 
(sociedades punitivistas) com profunda capacidade de naturalizar a violência bruta do sistema penal (BARATTA, 2002, p. 649).

Esse ideal acerca da prisão e da pena retrata e resume o pensamento da própria sociedade relacionado ao assunto, já que é uma maneira eficaz e célere de apartar "os outros" da sociedade e não se discutir os problemas que originam esse cenário.

Seguindo neste pensamento, pode-se concluir que, atualmente, as prisões consistem, de acordo com Carvalho (2010), em "[...] mecanismos de gestão da miséria e dos grupos inconvenientes representados pelos mal-adaptados e desajustados sociais [...]" (CARVALHO, 2010, p. 29), as quais servem, na verdade, para castigar os apenados, sendo equiparadas, muitas vezes, a verdadeiros campos de concentração nazistas.

Como consequência desse cenário, para prejuízo da sociedade, em função da pressão exercida pela criminologia midiática e sua consequente influência nas pessoas, que não possuem o conhecimento jurídico e técnico, infelizmente, em grande parte, o poder judiciário tem cedido às pressões punitivistas realizadas pela sociedade de um modo geral e, por consequência, aumentado a desigualdade no Brasil. De ultima ratio, o direito penal passa a prima ratio, deixando de ser instrumento subsidiário na proteção de interesses ou bens jurídicos.

Prova disso, é que desde o ano de 2014 a população de pessoas privadas de liberdade no Brasil é a terceira maior do mundo, somente com número total inferior ao presenciado nos Estados Unidos e na China (CNJ, 2014). Todavia, enquanto nestes outros dois países o número total de encarcerados tem diminuído nos últimos anos, no Brasil a situação é inversa. Como se não bastasse, o Brasil apresenta índice de reincidência no cometimento de crimes de cerca de $80 \%$, estando entre os três países no mundo que, na última década, mais encarceraram, juntamente com Camboja e El Salvador (WALMSLEY, 2016).

Por conseguinte, além do previsto no suscitado movimento lei e ordem, existe expoente na construção doutrinária acerca da beligerância penal como dogmática penal. Trata-se de Günther Jakobs, através da teoria intitulada do direito penal do inimigo, com proximidade ao sistema de variadas velocidades sustentado por Silva Sánchez (2001), resultando num direito penal de terceira velocidade, temática que será posteriormente abordada detalhadamente no presente trabalho.

Uma vez ultrapassada a análise dos problemas que assolam a aplicação da justiça penal brasileira, faz-se mister compreender a distinção entre a teoria do direito penal do inimigo e do cidadão, a tese defendida pelo professor Günther Jakobs, as principais críticas e exemplos de situações no ordenamento jurídico nacional que demonstrem resquícios desta tese, posto que a mesma se apresenta como um possível desdobramento do já constatado e explicitado encarceramento em massa que tem ocorrido no cenário brasileiro. 


\section{A Teoria do Direito Penal do Inimigo e suas principais críticas}

De acordo com Silva Sánchez (2002), cinde-se a expansão do direito penal em três etapas, ocorrendo o avanço nos estágios de acordo com o rigor dos princípios de garantia e das regras de imputação. A primeira etapa estaria relacionada ao Direito Penal tradicional, centrando-se em princípios garantistas rígidos e em intransigentes regras de atribuição de responsabilidade, apresentando-se como objetivo primordial o cumprimento de uma pena privativa de liberdade. Já na segunda etapa, tem-se o aproveitamento de penas distintas das privativas de liberdade, exemplificada através dos juizados especiais criminais no Brasil, apresentando como característica, sinteticamente, uma flexibilização dos princípios de garantia e de imputação da responsabilidade. A terceira e última etapa é a que se aborda neste trabalho, qual seja, o direito penal de terceira velocidade, também descrito como direito penal do inimigo, ocorrendo aplicação de penas com restrição de liberdade, todavia, defendendo que sejam diminuídas as garantias para que essa finalidade seja atingida (MOURA, 2009).

Foi numa conferência apresentada no congresso de penalistas alemães, em Frankfurt, no ano de 1985, que Günther Jakobs difundiu pela primeira vez a teoria do direito penal do inimigo Feindstrafrecht, para descrever um sistema antagônico ao direito penal do cidadão. O referido conceito gerou crescente debate científico e político, posto que nos momentos ulteriores Jakobs suscitou este conceito não mais em tom de crítica, iniciando a descrever uma maneira mais aprovadora e legitimadora de sua existência (NERY, 2016).

Em outra conferência, já no ano de 1999, em Berlin, Jakobs defendeu a instituição do direito penal do inimigo como outra classe do direito penal, ou seja, com significativa representatividade no ordenamento jurídico. Sobre isso, Muñoz Conde (1997) sustentou que:

[...] la necesidad de un derecho penal del enemigo [...] sino como otra clase de Derecho penal, sin duda desagradable, pero inevitable, al que a veces tiene que recurrir la sociedad para el mantenimiento de la seguridad cognitiva frente a los que de un modo permanente se mantienen al margen del sistema social y lo atacan. La característica de este Derecho no sería ya sólo la anticipación de su intervención en hechos alejados de la puesta en peligro de bienes jurídicos, sino también la utilización de penas draconianas, más allá de la idea de proporcionalidad, y la derogación o reducción de algunas de las garantías que concede el Estado de Derecho al imputado en el proceso penal (MUÑOZ CONDE, 1997, p. 336).

Portanto, inicialmente Jakobs usou a expressão direito penal do inimigo numa crítica ao crescimento do rigor aplicado nas legislações e políticas criminais da época, todavia, centrando-se sua tese numa tentativa de resposta ao desenvolvimento dos atentados terroristas, modificou o enfoque de sua teoria, no intuito de defender a sua legitimidade parcial, como modo de deter o aumento do próprio direito penal do inimigo (ZAFFARONI, 2007). 
Jakobs e Cancio Meliá (2009) afirmaram que o Estado deve agir de modo distinto e de acordo com os delinquentes que estiver julgando no caso concreto. Definem-se os criminosos de acordo com as relações que os mesmos apresentem, tanto perante o ordenamento jurídico, quanto à sociedade, separando-se os indivíduos em sujeitos de direitos e deveres inseridos na ordem jurídica (seres humanos com personalidade e direitos: pessoas) e indivíduos que se inserem excluídos da ordem jurídica (sem personalidade e direitos: inimigos). Ocorre o ingresso e a passagem do estágio de cidadão para inimigo por intermédio da habitualidade no cometimento de crimes, delinquência profissional e associação em organizações criminais.

No intuito de encontrar e suscitar precedentes filosóficos a fim de justificar a distinção dessas duas categorias de seres humanos, os racionais (cidadãos) e os ameaçadores (inimigos), Jakobs (2004) retrocedeu, indo na filosofia jurídica existente nos séculos XVII e XVIII. A teoria do direito penal do inimigo consiste, sinteticamente, em cindir o direito penal em dois sistemas, aptos para compreender e julgar duas categorias distintas de seres humanos, as quais apresentam fundamentais diferenças: os cidadãos e os inimigos, em que os postulados variam partindo, respectivamente, dos princípios do democrático direito penal do fato e da culpabilidade para um criticado direito penal do autor e da periculosidade.

De acordo com Santos (2013), a proposta de Jakobs passaria ao largo das teorias do conflito da moderna sociologia:

[...] fundadas nas contradições econômicas e políticas do modo de produção da vida material das sociedades humanas, preferindo o consenso da velha teoria do contrato social para definir sociedade e Estado - o que pode explicar algumas ideias rudimentares sobre crime e criminoso que inspiram a proposta. Assumindo a teoria do consenso como método de trabalho, aproveita para lembrar que todos os criminosos seriam inimigos da sociedade, conforme ROUSSEAU - ou feras, segundo FICHTE -, contra os quais se aplicaria um jus belli pela violação do consenso (LEIBNIZ), o pressuposto natural do contrato social. JAKOBS, contudo, não classifica como inimigos todos os autores de crimes: declara preferir as ideias mais moderadas de KANT e de HOBBES, que distinguiriam entre criminosos e inimigos, permitindo classificar os criminosos em (a) autores de fatos normais (punidos como cidadãos) e (b) autores de fatos de alta traição (punidos como inimigos) (SANTOS, 2013, p. 374).

Jakobs (2004) acolheu a definição formal de crime, instituída por Hegel, através da qual se entende o mesmo como sendo a negação de validade da norma, atualizada para redefinir a pena com duas formas distintas de tratamento e consequências, já que: a) Para o cidadão: considera-se que ele é um autor de crimes normais, apresentando o discernimento para se manter na condição de ser portador de direitos, pois não apresenta real risco ao sistema social. Trata-se de um cidadão que cometeu um deslize, mas, que é reparável. A pena é uma reação em face de um fato negativo cometido, com um caráter simbólico, num intuito de reafirmação da norma jurídica, como contradição ao fato passado do crime; b) Para o inimigo: enquadra-se nessa condição quem continuamente se afasta dos valores 
fundamentais da sociedade e passa a integrar organizações criminais. Para quem se enquadra na definição de inimigo, a pena apresenta um caráter bem distinto do suscitado anteriormente, sendo de castigo físico, um empecilho antecipado ao fato futuro criminoso, pretendendo-se com isso, portanto, prevenir uma futura negação da validade da norma a ser realizada pelo inimigo.

Existem fundamentais diferenças quanto a aspectos processuais entre o direito a ser aplicado para o cidadão ou para o inimigo. $\mathrm{O}$ sistema processual penal seria de imputação fundada no princípio acusatório para o cidadão, mediante respeito às garantias do devido processo legal, destacando-se a ampla defesa, presunção de inocência, e da imputação baseada no princípio inquisitório para o inimigo, sem o respeito às garantias anteriormente elencadas, contando, por exemplo, com investigações ou inquéritos secretos, vigilâncias sigilosas, interceptação telefônica, proibição de contato com advogado.

Além disso, o direito penal do inimigo se baseia em suposições e presunções, com a ausência de padrão objetivo, objetivando, também, punir o inimigo por fatos futuros e (in)certos que possa praticar. Para Jakobs e Cancio Meliá (2009, p. 23):

[...] nesse caso, a perspectiva não só contempla retrospectivamente o fato passado que deve ser submetido a Juízo, mas também se dirige - e sobretudo - para frente, ao futuro, no qual uma tendência a cometer fatos delitivos de considerável gravidade poderia ter efeitos perigosos para a generalidade (CANCIO MELIÁ, 2009, p. 23).

Nesse contexto surge uma das mais contundentes críticas à teoria do direito penal do inimigo, posto que com a aplicação da referida teoria, fere-se o Estado democrático de direito, dado ao fato de que não é preservada a igualdade, liberdade e, principalmente, a dignidade da pessoa humana, posto que coisifica o inimigo não mais o tratando como pessoa, nem com os seus direitos inerentes. É importante observar que o processo penal, além de ser uma forma de viabilizar a aplicação do direito penal, deve ser um meio apto para a garantia dos direitos do acusado, devendo coibir abusos e penas cruéis, por exemplo. Portanto, a justiça penal deve ser centrada na ideia de defesa dos direitos fundamentais, não devendo se submeter a uma política criminal maximalista, vingativa e com restrição de garantias inerentes a todas as pessoas.

Além disso, outra crítica para a teoria do direito do inimigo se refere à desproporcionalidade das penas impostas àqueles considerados pelo Estado como inimigos, as quais invariavelmente serão demasiadamente desproporcionais aos atos praticados. A desproporcionalidade é constatada na medida em que a criminalização das condutas no cenário prévio não é seguida de uma redução da pena com respeito àquela fixada para fatos consumados ou tentados. Assim, não se pune a conduta do agente e sim a sua mera periculosidade, logo, não há o respeito aos princípios da razoabilidade e da proporcionalidade. 
Da referenciada desproporcionalidade e falta de razoabilidade na aplicação das penas também surge a crítica de que a referida teoria institui um estado de guerra. Partindo-se da premissa da teoria de que o inimigo sequer deve ser entendido como uma pessoa pelo Estado, mas sim, como um perigo que deve ser combatido e neutralizado na sociedade que integra, a ele não se estendem alguns direitos e garantias, que pertenceriam somente aos cidadãos. De tal maneira, o Estado não precisa preocupar-se em assegurar, por exemplo, o seguimento do devido processo legal, reputando-se como válidas quaisquer atitudes que visem tornar a ameaça inofensiva.

Porém, ainda que na teoria do direito penal do inimigo esteja previsto um tratamento distinto para inimigos e cidadãos, permite-se que ambos os direitos penais funcionem na mesma perspectiva do Estado de direito. Por conseguinte, sinteticamente, tem-se que, para Jakobs, o objeto do direito penal seria a proteção da estrutura normativa que assegura a relação entre as pessoas. Já a pena cumpre a função de reafirmar a vigência da norma (ZAFFARONI, 2007).

É interessante refletir sobre quem efetivamente seriam os inimigos. Jakobs apresentou exemplos, invariavelmente, ligados ao terrorismo. Trazendo-se a temática para a realidade brasileira, Greco (2010) questionou se os traficantes nos grandes centros urbanos poderiam ser configurados como os inimigos, dado seu poder e representatividade. Mas, seriam somente eles que integrariam a lista? A resposta é precisa:

Quem são os inimigos? Alguns, com segurança, podem afirmar: os traficantes de drogas, os terroristas, as organizações criminosas especializadas em sequestro para fins de extorsões. E quem mais? Quem mais pode se encaixar no perfil do inimigo? Na verdade, a lista nunca terá fim. Aquele que estiver no poder poderá, amparado pelo raciocínio do Direito Penal do Inimigo, afastar o seu rival político sob o argumento de sua falta de patriotismo por atacar as posições governamentais. Outros poderão concluir que também é inimigo o estuprador de sua filha. Ou seja, dificilmente se poderá encontrar um conceito de inimigo, nos moldes pretendidos por essa corrente, que tenha o condão de afastar completamente a qualidade de cidadão do ser humano, a fim de tratá-lo sem que esteja protegido pelas garantias conquistadas ao longo dos anos (GRECO, 2010, p. 24).

Como consequência esperada, houve ampliação do conceito inicialmente previsto para designar o inimigo, ultrapassando-se os integrantes, inicialmente previstos como os grupos terroristas, fixados por Jakobs, para também passar a constar os demais integrantes de organizações criminosas organizadas. Assim, legitima-se a política da expansão da punitividade com a radical ruptura dos sistemas de garantias. De acordo com Carvalho (2006, p. 259):

A beligerância do discurso penal do inimigo transpõe as ações de desrespeito aos direitos exercidas pelas agencias repressivas (ilegalidades toleradas), do plano fático ao discurso legitimador, abrindo espaços para a justificação do terrorismo de Estado (direito penal do terror) através da aplicação do direito penal (do inimigo). Neste quadro de apontamento de exceções que se tornam duradouras, a categoria normatizada 'organizações criminosas' adquire fundamental importância, visto ser 
o conceito que possibilitará agregar sob o mesmo estilo repressivo condutas absolutamente diversas como 'terrorismo', comercio de drogas ilícitas, imigração ilegal, tráfico de pessoas e de órgãos, crimes econômicos entre outros (CARVALHO, 2006, p. 259).

Assim, prosseguiu Carvalho (2006) em sua crítica, no sentido de suscitar que ao se definir grupos com potencialidade delitiva, destituindo seus componentes do status de pessoa, abdica-se da própria noção de Estado democrático de direito. Ressalta-se, ainda, que apenas nos projetos políticos-totalitários (Estados de exceção) o sentido absoluto da segurança pública ultrapassa a dignidade da pessoa humana, dada a importância e representatividade que o princípio da dignidade da pessoa humana detém.

Veja-se o entendimento de Arbage e Vasconcellos (2017) quanto aos requisitos para a configuração de um Estado democrático de direito:

\begin{abstract}
Constata-se como alguns dos requisitos para a configuração de um Estado Democrático de Direito, a existência e o respeito aos princípios da dignidade da pessoa humana, da igualdade e legalidade. Neste sentido, o sistema e o processo penal, da mesma forma, devem estar em compasso com os referidos princípios e a possibilidade de proporcionar educação aos jovens e adultos privados de liberdade é algo elementar, básico e imprescindível no sentido de conferir dignidade, oportunidade de vida e diminuição da desigualdade social (ARBAGE; VASCONCELLOS, 2017, p. 37).
\end{abstract}

Nesse sentido, importante reflexão sobre a teoria do direito penal do inimigo é que a mesma aflora a já existente seletividade do poder punitivo, porquanto, estabelece que o Estado tem a discricionariedade de delimitar quem serão os inimigos, ampliando-se a possibilidade de segregar e aflorar as desigualdades sociais, de oportunidades e econômicas.

Quanto à classificação de Zaffaroni; Batista; Alagia; Sloker (2003) iminalizado se vê apenado, pois a visão geral é de que o mesmo é um ser inferior, porquanto "[...] o discurso do direito penal de autor propõe aos operadores jurídicos a negação de sua própria condição de pessoas [...]" (ZAFFARONI; BATISTA, 2003, p. 132), o que configura a referida sensação de se enxergar como um inimigo. Jakobs e Cancio Meliá (2007) referenciaram que existem distinções estruturais entre o direito penal comum e o direito penal do inimigo. $\mathrm{O}$ direito penal do inimigo estigmatiza alguns grupos de infratores ao invés de fixar normas (prevenção geral positiva), razão pela qual se conclui que o direito penal do inimigo não é um direito penal do fato (Tatstrafrecht), mas, do autor (Täterstrafrecht).

No direito penal do fato o sujeito passivo de um crime é julgado em razão dos fatos que lhe são imputados. Sua personalidade e demais peculiaridades relacionadas são utilizadas somente na dosimetria da pena. Todavia, o direito penal do autor tem diferenças significativas, já que o fato praticado pelo individuo não é o que vai definir seu julgamento, mas sim, a sua personalidade. Nesse aspecto, reside outra crítica à teoria do direito penal do inimigo, posto que traduz em afronta ao princípio da lesividade, que é primordial para a legitimidade da intervenção penal. 
Segundo Batista (2007, p. 93), o direito penal só pode ser direito penal de ação, fundamentando sua crítica no seguinte sentido:

O direito penal só pode ser um direito penal da ação, e não um direito penal do autor, como eventualmente se pretendeu. 'O homem responde pelo que faz e não pelo que é', frisa Cunha Luna. Com exatidão lembra Mayrink da Costa que 'o direito penal do autor é incompatível com as exigências de certeza e segurança jurídicas próprias do estado de direito'. Isso não significa que o sujeito determinado não interesse de nenhuma forma. Ao contrário, o homem e sua existência social concreta devem estar no centro da experiência jurídico-penal, particularmente nas áreas da culpabilidade e da aplicação e execução da pena. O que é vedado pelo princípio da lesividade é a imposição de pena (isto é, constituição de um crime) a um simples estado ou condição desse homem, refutando-se, pois, as propostas de um direito penal do autor e suas derivações mais ou menos dissimuladas (tipos penais de autor, culpabilidade pela conduta ao longo da vida, etc) (BATISTA, 2007, p. 93).

Reconhece-se que pode ser viável que com penas desmedidas e restrições a direitos e garantias constitucionais se possa guerrear contra o inimigo, todavia o importante é refletir acerca do preço que isso seria feito, já que é possível uma união entre um direito penal de intuito autoritário, conflitante com o Estado de direito, assim como as legislações excepcionais das ditaduras ou de regimes de exceção. Esse também é o entendimento de Faraldo Cabana (2004, p. 316):

En esta labor se ha tener en cuenta la necesidad de evitar el peligro de caer en la tentación de la 'perenne emergencia', pues la experiencia demuestra que la creación de una legislación excepcional para una situación que se define como extraordinaria, como sucede con la lucha contra el terrorismo y/o la delincuencia organizada, acaba convirtiendo-se en el modelo de la legislación 'normal', a la que inevitablemente contagia (FARALDO CABANA, 2004, p. 316).

Resta cristalino que o Direito Penal de inimigo além de ser arbitrário e desumano, apresenta perigo e ilegalidade significativos, na medida em que desrespeita princípios básicos de convivência social em um Estado social e democrático de direito.

\section{Conclusão}

A principal tarefa do Direito Penal é localizar os atributos que proporcionem eficácia na persecução punitiva da criminalidade, todavia, devem-se respeitar as garantias constitucionais inseridas no ordenamento jurídico, como forma de coibir abusos por parte do Estado e se proporcionar um estágio de dignidade da pessoa humana e direitos básicos intactos.

Os meios de comunicação são importantes instrumentos para a construção das ideologias. Todavia, constata-se uma dramatização midiática acerca da insegurança pública, realizando-se um discurso do inimigo em relação ao acusado, não sendo incomum ver manifestações defendendo a flexibilização de seus direitos e garantias fundamentais. 
Portanto, além de ocorrer uma supervalorização da criminalidade, existe uma estigmatização de determinadas parcelas populacionais que são convertidas para a condição de inimigos da sociedade.

Assim, propaga-se e se promove uma expansão do poder punitivo estatal, defendida como a solução para uma aludida criminalidade exacerbada. Para tanto, criam-se leis, aumentamse penas, e direitos e garantias constitucionais são abolidos para, hipoteticamente, se assegurar a segurança da sociedade. Esse é um dos sérios problemas enfrentados pelo Direito Penal contemporâneo, posto que o senso comum prega que somente o recrudescimento das leis e penas solucionaria o problema da criminalidade. Todavia, em um Estado democrático de direito, a Justiça Penal não deve pautar sua atuação com base na opinião pública e no midiatismo dos meios de comunicação, até pelo fato de que essa é uma visão simplista e imediatista acerca do problema da criminalidade.

Conforme explicitado, a proposta apresentada por Jakobs, acerca da criação de um Direito Penal do inimigo, é defendida em razão de uma hipotética prevenção da criminalidade e diminuição das condutas de pessoas que apresentem maiores riscos e periculosidade. Com isso, altera-se a perspectiva clássica de punição pelo fato praticado para se punir a partir da conduta e hipotética periculosidade que o cidadão apresenta. Todavia, entende-se que esse não é o caminho adequado, pois não é através da legitimação de discursos de ódio e segregação que o cenário será melhorado, devendo-se respeitar as garantias fundamentais conquistadas ao longo da evolução humana.

Diante do exposto, entende-se que a Justiça Penal deve se basear num posicionamento político-criminal minimalista e garantista, condizente com o Estado Democrático de Direito, com o propósito de prevenção geral dos crimes, vedando as penas cruéis e condições insalubres e degradantes no sistema prisional, utilizando-se das penas e medidas alternativas, no intuito de formar uma justiça restaurativa.

Martin Luther King já afirmava que a medida de um homem não se vê na forma como ele se porta em momentos de conforto e conveniência, mas, em como se mantém em tempos de controvérsia e desafio. Sabe-se que no senso comum é cada vez mais frequente o discurso do ódio e da punição sem medidas, para as pessoas que figuram na condição de apenados, todavia, conclui-se, quanto à teoria do Direito Penal do inimigo e sua aplicabilidade, que é extremamente nefasto o preconizado na mesma, quanto ao desrespeito às garantias constitucionais do devido processo legal, aplicáveis somente ao cidadão e negadas ao inimigo. Considera-se ser um risco exacerbado conferir o poder discricionário ao Estado, no intuito de definir quem serão os inimigos, sendo situações incompatíveis com qualquer país que se intitule como sendo um Estado Democrático de Direito. 


\section{Referências}

ARBAGE, L. A.; VASCONCELLOS, R. da C. Educação de jovens e adultos privados de liberdade na américa latina: uma alternativa de (re) começo. Prim@ Facie-Direito, História e Política, João Pessoa, v. 16, n. 33, p. 1-45, 2017.

BARATTA, A. Criminologia Crítica e Crítica do Direito Penal: introdução à Sociologia do Direito Penal. 3. ed. Rio de Janeiro: Revan, 2002.

BATISTA, N. Introdução crítica ao Direito Penal Brasileiro. 11. ed. Rio de Janeiro: Revan, 2007.

BRASIL. Presidência da República. Lei n. 11.343, de 23 de agosto de 2006. Institui o Sistema Nacional de Políticas Públicas sobre Drogas - Sisnad; prescreve medidas para prevenção do uso indevido, atenção e reinserção social de usuários e dependentes de drogas; estabelece normas para repressão à produção não autorizada e ao tráfico ilícito de drogas; define crimes e dá outras providências. Diário Oficial da União, Brasília (DF), 23 ago. 2006. Disponível em: http://www.planalto.gov.br/ccivil_03/_ato20042006/2006/lei/l11343.htm. Acesso em: 11 mar. 2019.

BRASIL. Presidência da República. Código Penal. Decreto-Lei 2.848, 7 de dezembro de 1940. Rio de Janeiro: Diário Oficial da União, Brasília (DF), 31 dez. 1940. Disponível em: http://www.planalto.gov.br/ccivil_03/decreto-lei/Del2848compilado.htm. Acesso em: 11 mar. 2019.

BOLDT, R.; KROHLING, A. Entre cidadãos e inimigos: o discurso criminalizante da mídia e a expansão do direito penal como instrumentos de consolidação da subcidadania. Direitos Fundamentais e Sociedade, Curitiba: Unibrasil, v. 4, 2008.

CARVALHO, S. O encarceramento seletivo da juventude negra brasileira: a decisiva contribuição do poder judiciário. Revista da Faculdade de Direito da UFMG, v. 67, p. 623-652, 2015.

CARVAlHO, S. O Papel dos Atores do Sistema Penal na Era do Punitivismo: O Exemplo Privilegiado da Aplicação da Pena. Rio de Janeiro: Lumen Juris, 2010.

CARVALHO, S. Política de guerra às drogas na América Latina: entre o direito penal do inimigo e o estado de exceção permanente. Crítica Jurídica, v. 25, p. 261-276, 2006.

CNJ, Conselho Nacional de Justiça. Brasília (DF), 2014. Disponível em:

http://www.cnj.jus.br/component/acymailing/archive/view/listid-4-boletim-domagistrado/mailid-5632-boletim-do-magistrado-09062014. Acesso em: 30 mar. 2019.

DURKHEIM, E. Da divisão do trabalho social. 2. ed. Trad. Eduardo Brandão. São Paulo: Martins Fontes, 1999. 
FARALDO CABANA, P. Nuevos retos del derecho penal en la era de la globalización. Valencia: Tirant lo Blanch, 2004.

FBPS, Fórum Brasileiro de Segurança Pública, 13ª edição, ano 2019, ISSN 1983-7364, disponível em: www.forumseguranca.org.br.

GRECO, R. Direito penal do equilíbrio: uma visão minimalista do direito penal. 5. ed. Niterói: Impetus, 2010.

HOBBES, T. De Cive: elementos filosóficos a respeito do cidadão. Tradução de Ingeborg Soler. Petrópolis, RJ: Vozes, 1993.

HUNGRIA, N. Comentários ao código penal. 5. ed. v.1. Tomo II. Rio de Janeiro: Forense, 1978.

INFOPEN. Departamento Penitenciário Nacional. Levantamento nacional de informações penitenciárias (Infopen). 2017. Disponível em: http://depen.gov.br/DEPEN/noticias-1/noticias/infopen-levantamento-nacional-deinformacoes-penitenciarias-2016/relatorio_2016_22111.pdf. Acesso em: 31 maio 2019.

JAKOBS, G. Bürgerstrafrecht und Feindstrafrecht. HRRS, Caderno 3, p. 88-95, März. 2004. Disponível em: http://www.hrr-strafrecht.de/hrr/archiv/o4-03/indez.php3?seite=6. Acesso em: 31 maio 2019.

JAKOBS, G.; CANCIO MELIÁ, M. Direito penal do inimigo: noções e críticas. 4. ed. Tradução André Luís Callegari. Porto Alegre: Livraria do Advogado, 2009.

JAKOBS, G.; CANCIO MELIÁ, M. Direito Penal do Inimigo: noções e críticas. Traduzido por André Luís Callegari e Nereu José Giacomolli. 2. ed. Porto Alegre: Livraria do Advogado, 2007.

MOURA, B. A expansão do direito penal: modelos de (des)legitimação. Revista CEPPG, Catalão, n. 21. 2009. Disponível em:

http://www.portalcatalao.com/painel_clientes/cesuc/painel/arquivos /upload/temp/d9023eec1397674106956b1f2cf36b82.pdf. Acesso em: 4 jun. 2019.

MUÑOZ CONDE, F. Comentarios a los Congresos de Trento y Frankfurt sobre el "Derecho Penal del enemigo". Revista Penal, Madrid, v. 18, 1997.

NERY, D. C. P. Direito penal do inimigo x direito penal do cidadão. Conpedi Law Review, Florianopólis, v. 1, n. 10, p. 101-131, 2016. 
SANTOS, J. C. dos. O direito penal do inimigo ou o discurso do direito penal desigual. Direito, v. 20, 2013. Disponível em: https://cirino.com.br/artigos/. Acesso em: 5 maio 2019.

SILVA SÁNCHEZ, J.-M. A expansão do direito penal: aspectos da política criminal nas sociedades pós industriais. Traduzido por Luiz Otavio de Oliveira Rocha. São Paulo: Revista dos Tribunais, 2002.

SILVA SÁNCHEZ, J. -M. La Expansión Del Derecho Penal. 2. ed. Madrid: Civitas, 2001.

ZAFFARONI, E. R. O inimigo do Direito Penal. Rio de Janeiro: Revan, 2007.

ZAFFARONI, E. R.; BATISTA, N. Direito Penal Brasileiro. Rio Janeiro: Revan, 2003.

ZAFFARONI, E. R.; BATISTA, N.; ALAGIA, A.; SLOKAR, A. Direito Penal Brasileiro: teoria geral do direito penal. v. I, 3. ed. Rio de Janeiro: Revan, 2003.

WALMSLEY, R. World Prison Population List. 11 ed. London: International Centre for Prison Studies.- Kings College, 2016. Disponível em:

www.prisonstudies.org/sites/default/files/

resources/downloads/word_prison_population_list_11th_edition.pdf. Acesso em: 5 maio 2019.

\section{Lucas Andres ARBAGE}

Graduação em Direito pela Faculdade Metodista de Santa Maria (FAMES). Especialista em Direito Penal e Processo Penal, abordando a temática do foro por prerrogativa de função; também é especialista em Direito Civil e Empresarial, com a temática do marco civil da internet, ambas pela Faculdade de Direito Damásio de Jesus. Mestre em Educação, pela Universidade Federal da Fronteira Sul (UFFS), com sua dissertação acerca da reintegração social dos apenados por meio da educação. Advogado, inscrito na Ordem dos Advogados do Brasil

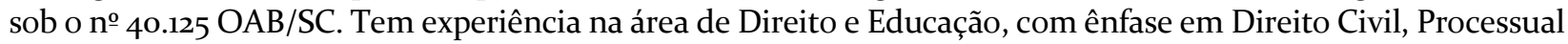
Civil, Consumidor, Processual Penal e Penal e Políticas Públicas. 